\title{
INSTITUIÇÃO PENITENCIÁRIA E \\ TRABALHO: A RESSOCIALIZAÇÃO COMO IDEOLOGIA DE CONTROLO SOCIAL*
}

\author{
Rodrigo Oliveira Santana $a^{(1)}$
}

INSTITUCIÓN PENITENCIARIA Y TRABAJO: LA RESOCIALIZACIÓN COMO IDEOLOGÍA DE CONTROL SOCIAL

PENITENTIARY INSTITUTION AND WORK: RE-SOCIALIZATION

AS AN IDEOLOGY FOR SOCIAL CONTROL

Fecha de recepción: 25 de agosto de 2016

Fecha de aprobación: 04 de octubre de 2016

\section{Sugerencia de citación:}

Oliveira Santana, R. (2017). Instituição penitenciária e trabalho: A ressocialização como ideologia de controlo social. Razón Crítica, 2, 79-106, doi: http://dx.doi.org/10.21789/25007807.1180

\footnotetext{
* Este artigo é fruto de uma investigação doutoral desenvolvida na Universidade de Coimbra (Portugal), orientada pelo Professor Doutor Paulo Peixoto da Faculdade de Economia.

(1) Docente da Faculdade Metropolitana da Amazônia e da Universidade Estácio de Sá Castanhal (Pa) (Brasil), Advogado, Mestre em Direito do Estado pela Universidade da Amazônia e Doutorando em Sociologia pela Universidade de Coimbra (Portugal) e Doutorando em Ciências Sociais da Universidade Federal do Pará (Brasil). http://orcid.org/0000-0002-4383-3454

Correio eletrônico: adv.rsantana@gmail.com
} 


\section{R E S U M O}

Este trabalho reflete nas conexões entre o capitalismo e o cárcere como instituição social, para discorrer sobre a racionalidade do trabalho social penitenciário como tecnologia de tratamento de ressocialização dentro de uma estrutura social regida pela eficiência produtiva. A instituição penitenciária desempenha um importante papel de adestramento, diminuindo a resistência às condições de trabalho, o qual é elevado à categoria de principal elemento ressocializador. Neste contexto, questionam-se também os números de uma nova modalidade de trabalho penitenciário -o trabalho consensual- implementada no Estado do Pará (Brasil), a partir do programa "Começar de Novo". Apresenta-se para tal fim, uma nova metodologia que captura individualmente aquelas disposições pessoais que indicam o sucesso (ou falência) de uma política pública voltada para a questão carcerária.

PALAVRAS-CHAVE: instituição penitenciária, trabalho penitenciário, controlo social. 


\section{R E S U M E N}

Este trabajo reflexiona sobre las conexiones entre el capitalismo y la cárcel como institución social, y sobre la racionalidad del trabajo social penitenciario como tecnología de tratamiento penitenciario resocializador dentro de una estructura social regida por la eficiencia productiva. La institución penitenciaria desempeña un importante papel en la disminución de la resistencia humana ante las condiciones de trabajo, el cual es considerado como principal elemento resocializador. En este contexto se cuestionan las estadísticas de la política pública "Começar de Novo" en el Estado de Pará (Brasil), que representa una nueva modalidad de trabajo penitenciario -el trabajo consensual-y se introduce una nueva metodología capaz de capturar individualmente las disposiciones personales que indican el éxito o fracaso de una política pública penitenciaria.

\section{PALABRAS CLAVE: institución penitenciaria, trabajo penitenciario, control social.}

\section{A B S T R A C T}

This paper reflects on the connections between capitalism and the prison as a social institution, and on the rationality of penitentiary social work as a technology for the penitentiary re-socializing treatment within a social structure ruled by productive efficiency. The penitentiary institution carries out an important role in the reduction of human resistance in face of work conditions, which is considered a main re-socializing element. In this context, the "Começar de Novo" public policy statistics in the State of Pará (Brasil) are questioned, which represents a new method in penitentiary work -consensual work- and introduces a new methodology that is capable of individually capturing the personal dispositions that indicate the success or failure of a penitentiary public policy.

KEYWORDS: penitentiary institution, penitentiary work, social control. 


\section{N T R O D U Ç Ã O}

Percebendo a pena como um fenômeno social, e não mais como uma mera consequência do delito, é possível estabelecer uma relação entre os métodos de punição e as práticas de tratamento das pessoas submetidas a um castigo que as priva de algum direito. Designadamente, e de forma mais corrente, o direito à liberdade. É também possível constatar que a instituição penitenciária se desenvolve de maneira independente da ideia de punição como pena. Aplicadas à sanção penal, uma série de técnicas -autodenominadas ressocializadoras- são postas em prática para alcançar uma reintegração social e moral da pessoa. Um dos tratamentos ressocializadores mais importantes, que conseguiu resistir ao tempo como técnica primordial, é o trabalho penitenciário, o qual se constitui em objeto da investigação inerente ao presente artigo. E ainda que se vejam emergir fórmulas ressocializadoras baseadas na educação ( $c f r$. Onofre e Julião, 2013), ou nas artes ( $c f r$. Lima, Oliveira e Wilrich, 2012), por exemplo, em contextos de reclusão, o trabalho mantem uma aura suprema como solução para o desiderato da reintegração.

O trabalho penitenciário é uma técnica antiga, desde sempre apresentada numa perspectiva positiva e entusiasmadora. Porém, esconde-se sempre por detrás de uma realidade produtiva que, por conta da relação penitenciária, desenvolve sutis formas de controlo ${ }^{1}$,

1 As ideias de controlo são desenvolvidas a partir de perspectivas sociológicas. 
as quais correspondem a um propósito estrutural quase nunca notado. Esta técnica penitenciária avança na história da instituição desde o trabalho forçado até o trabalho consensualizado como mecanismo primordial de reintegração. Este último surge como uma promissora intenção de buscar uma relegitimação social do tratamento penitenciário através do trabalho. Para tal fim, procurase gerar um consenso entre o poder público e a pessoa reclusa.

Este artigo tem o propósito de apresentar o arcabouço teórico e metodológico desenvolvido na produção da correspondente tese doutoral parcial na Universidade de Coimbra, em razão da inquietude em saber qual foi a racionalidade mobilizada que permitiu que o trabalho persistisse no tempo como principal elemento de tratamento penitenciário²; qual é a sua relação com a estrutura social; e, a partir daí, analisar preliminarmente se o trabalho penitenciário está ou não vocacionado para a vida laboral em liberdade. Do ponto de vista sociológico, tenta-se entender a escala macro de contextualização desta técnica. Isto permite perceber os efeitos produzidos nas pessoas reclusas, de modo a determinar, numa escala micro, o sucesso ou insucesso do projeto reinsersor do tratamento penitenciário em vista de sua nova (contemporânea) configuração pautada na consensualidade. A linha de pesquisa deste olhar longitudinal baseia-se na tese de que a persistência da técnica, não obstante sua transformação ao longo da história, se deve ao fato da ressocialização pelo trabalho funcionar persistentemente e de forma atualizada como ideologia de controlo social.

Através de uma breve abordagem histórica e teórica, exposta neste artigo, traçar-se-á uma evolução do trabalho como técnica de tratamento penitenciário, chegando à definição, por parte das Nações Unidas, de regras mínimas para o tratamento de pessoas

2 Registra Marques (2013, p. 138) que o trabalho sustentou-se no tempo como uma técnica de tratamento penitenciário. Após o surgimento do direito penitenciário como ciência no século XIX -o qual cria critérios, tanto para uma racionalização da administração penitenciária, como para a execução das penas ordinárias- o trabalho resiste até os conceitos que, oriundos da Escola Positiva da Criminologia Italiana, vieram a ser pouco estimulantes para um projeto de ajuda social, tais como "criminoso nato" e "criminoso incorrigível". Estes conceitos secundarizaram o papel de outras técnicas reabilitadoras, como a religião e a educação. Porém, mantém-se intacto o propósito ressocializador pelo trabalho: "Together with the notion of the failure of the prison rendered manifest through recidivism, the belief in the existence of 'incorrigibles' and 'constitutional criminals', whilst not always given scientific credibility, effected some loss of interest on the part of penologists with regard to the topic of 'rehabilitation'. From the classical recipe concerning the reform of criminals, only work, in reality, remained a central question". 
reclusas. Isto vem a representar um progresso evolutivo no sentido de garantir um maior respeito pelos direitos fundamentais subjetivos na relação penitenciária Estado-Pessoa: trata-se do trabalho consensual.

Exposto e problematizado o objeto, o estudo será centrado na política pública do trabalho consensual, a qual foi incorporada no Brasil através do programa "Começar de Novo"'. Em específico no Estado do Pará, o programa foi implementado pelo Conselho Nacional de Justiça, o qual tem como objetivos a promoção da cidadania e a prevenção da reincidência em crimes. Este programa tem como base epistemológica o designado consensualismo penitenciário, o qual pressupõe que, através de um acordo entre o sistema de justiça criminal e as entidades públicas e privadas, a pessoa reclusa possa ter, caso aceite, a oportunidade de trabalhar fora do estabelecimento. O termo "consensual" -que pressupõe um mínimo de discussão sobre a estrutura e as condições do trabalho entre a pessoa reclusa e o tomador do serviço- é uma prerrogativa do Poder Público, que acordará com os tomadores do serviço as condições do trabalho que será desenvolvido por um terceiro. À pessoa reclusa somente cabe acenar positiva ou negativamente se deseja trabalhar ou, pelo contrário, continuará a viver na instituição total. Devido à carga ideológica que transporta, vertida no subtítulo deste projeto, a ressocialização pelo trabalho torna-se o instrumento óbvio e, por tanto, "consensual", para converter os indivíduos à conformidade de uma ordem social ancorada no valor do trabalho como fator de integração e de honorabilidade social.

O estudo demonstrará as investigações bibliográficas para conhecimento dos trabalhos que foram desenvolvidos sobre o tema, o que possibilitará reforçar a pertinência do estudo; indicará a sociologia em escala individual como melhor técnica para a compreensão dos comportamentos das pessoas e do modo em que estes refletem os contextos sociais, culturais e econômicos na construção de percursos de vida. Finalmente, através do cruzamento destes dados, responder-se-á o principal questionamento: o trabalho penitenciário consensual está vocacionado à vida das pessoas reclusas?

3 Programa instituído através da Resolução 96 de 2009. Disponível em http://www.cnj. jus.br/sistema-carcerario-e-execucao-penal/pj-comecar-de-novo 


\section{Instituição penitenciária, pena e estrutura social}

Desenvolver um estudo sobre os sistemas punitivos parece, em princípio, uma orientação para se voltar a estudar as teorias do direito punitivo. Ou, como muitos preferem dizer, uma pesquisa para estudar as teorias da pena, tendo como perspectiva demonstrar como as penas foram usadas ao longo dos tempos de maneiras diversas, expondo as razões teóricas de aplicação das penas e fazendo sobressair o seu caráter evolutivo, o qual demonstra certo processo de humanização. A pena, abordada nas teorias do direito, é apresentada como uma entidade abstrata que evoluiu no tempo, mas pouco ou nada nos diz sobre as técnicas penitenciárias reinsersoras que têm um determinado tipo de propósito social.

As teorias das penas ${ }^{4}$ não estudam as técnicas penitenciárias "ressocializadoras", que hoje designamos por tratamento penitenciário. Portanto, estas teorias mostram-se incapazes de explicar os métodos punitivos que, dentro do contexto social, deram origem à própria instituição penitenciária. Daí torna-se relevante questionar este contexto a partir de perspectivas sociológicas.

A história da pena "precede a história do próprio delito" (Baratta, 1986, p. 79) e também da instituição penitenciária. Na Alta Idade Média (400 - 1000 d.C.), as condições de existência de um sistema punitivo estatizado estavam ausentes e os modos de resolução dos conflitos eram orientados pela riqueza social e o status que possuíam as pessoas envolvidas (Rusche e Kirchheimer, 1984, p. 7).

4 As teorias absolutas da pena a justificam como um fim em si mesmo, ou seja, a pena é uma resposta a um desvio (o qual nem sempre é um delito) e geralmente está fundamentada em atos divinos. Portanto, como corrobora Roxin (2004, p. 19), "a própria ideia de retribuição compensadora só pode ser plausível mediante um ato de fé. Pois, considerando-o racionalmente, não se compreende como se pode pagar o mal cometido, acrescentando-lhe um segundo mal, sofrendo a pena. É claro que tal procedimento corresponde ao arraigado impulso de vingança humana, do qual surgiu historicamente a pena". As teorias relativizadoras do absolutismo da pena, por sua vez, outorgam novos rumos ao sentido de punir, questionando qual a razão da punição. Nessa nova visão, a pena ganha uma orientação para o futuro, e serve como instrumento que permite evitar o delito e resguarda determinados bens jurídicos que se estimam necessários para a vida social. A pena não é mais um fim em si mesmo, mas um instrumento pelo qual busca-se reeducar a pessoa punida e "la sanción es algo más que mera retribución del daño, algo más que un mal. Según esta teoría, el delincuente tiene derecho a ser reeducado, y la sociedad también tiene derecho y obligación de resocializarle, aunque con los matices y limitaciones que corresponda en cada supuesto. La pena es no solo necesaria sino también beneficiosa. Si no es beneficiosa, tampoco es necesaria" (Beristain, 1982, p. 8). 
O direito penal apresentava-se como instrumento secundário destinado a preservar a hierarquia social ${ }^{5}$.

Dependendo da classe social dos envolvidos, o direito penal deixava espaço a uma contratualização do conflito, sendo a pena pecuniária a principal forma de restituição de um dano causado. Neste cenário, uma prestação pecuniária era dosada cuidadosamente segundo o status social do ofensor e da pessoa ofendida. Porém, se o ofensor não possuísse riquezas suficientes para saldar seu débito, o direito penal emergia aplicando-lhe uma pena corporal ${ }^{6}$ (privação de sua liberdade) com a consequente submissão ao cárcere ${ }^{7}$. O direito penal e o cárcere ${ }^{8}$ passam a atingir diretamente as pessoas oriundas das classes sociais mais baixas.

A partir de então, a pena transforma-se num instrumento de sujeição social, na medida em que os senhores feudais aumentavam seus poderes sobre as classes mais baixas através da sujeição econômica e com a possibilidade de transformar o sistema de justiça criminal num provedor de bens, já que, ao contrário do cenário que conhecemos, aqueles que eram submetidos a um processo pagavam fosse uma pena pecuniária ou a perda de alguns bens em favor da parte ofendida ${ }^{9}$. Numa última hipótese era aplicada a pena corporal.

5 Durante a Alta Idade Média "la tradición, un bien balanceado sistema de dependencias sociales y el reconocimiento religioso del orden de cosas establecido, constituían una protección efectiva y suficiente. El énfasis principal del derecho penal residía en el mantenimiento del orden público entre iguales en estatus y riqueza" (Rusche e Kirchheimer, 1984, p. 8).

6 A pena corporal tinha por finalidade uma correção alicerçada no arrependimento, ou seja, era um método usado para expiar a culpa e tinha como propósito submeter à pessoa a uma dor, vexame ou qualquer forma de suplício: "La penitencia, cuando se transformó en sanción penal propiamente dicha, mantuvo en parte su finalidad de corrección; en efecto, ésta se transformó en reclusión en un monasterio por un tiempo determinado. El aislamiento, el contacto con el culto y la vida religiosa, daban al condenado la oportunidad de expiar su culpa" (Melossi e Paravini, 1980, p. 22). 7 Rusche e Kirchheimer (1984, p. 9) relatam que "si el causante del hecho no podía pagar, recibía una pena privativa de libertad siendo enviado a prisión y alimentado con pan y agua hasta que los habitantes de la ciudad intercedieran por él o el obispo lo perdonara" e que "la pena de prisión era considerada en esa época como una forma de pena corporal".

8 Na estrutura social pré-capitalista o cárcere como instituição social não existia. Várias formas de cárcere existiam, como, por exemplo, o cárcere por dívidas. Porém, nenhum deles executava uma pena ordinária e autônoma, motivo pelo qual adota-se o entendimento de que a instituição penitenciária é uma evolução do cárcere (Melossi e Paravini, 1980, p. 19).

9 A punição podia ser cumulativa (perda de bens ou valores e prestação pecuniária), configurando-se assim uma verdadeira forma de aumento de patrimônio para as pessoas da classe social mais abastarda: "El pago a quienes administraban la ley u otorgaban a otros los poderes para hacerlo provenía de las cotas impuestas a quienes se encontraban bajo proceso, que se satisfacian en forma de confiscaciones o penas pecuniarias impuestas de manera conjunta o sustitutiva a la Penance debida a la parte injuriada" (Rusche e Kirchheimer, 1984, p. 10). 
Durante o século xv (1401 - 1500 d.C), a condição de vida das classes inferiores na Europa Central e do Norte, principalmente, começou a decair devido a um grande êxodo rural, com o consequente aumento da população urbana. A principal causa do êxodo foi a diminuição da produtividade da terra por conta do aprimoramento de um sistema de trocas que impôs uma brusca queda nos preços dos produtos dos trabalhadores da terra e que coincidiu com um aumento populacional, principalmente na Inglaterra ${ }^{10}$.

Nenhuma política capaz de enfrentar o problema foi posta em prática. O grande êxodo para a cidade em detrimento do desenvolvimento do comércio provocou o surgimento de um grupo que não conseguia trabalho, fosse porque a demanda por trabalho era superior ao que era oferecido, ou porque os trabalhadores rurais -agora no ambiente urbano- não aceitavam as condições de trabalho impostas. As ruas do ambiente urbano passaram a ser habitadas por uma grande massa de "mendigos" e de "vagabundos"11.

Com o aumento desenfreado da população urbana na Europa no final do século xv e início do século Xvi, legislações surgiram para tratar deste problema social. A solução dada pelo direito foi considerar o ócio um delito, já que muitos "vagabundos" não tinham autorização para mendigar. As penas ${ }^{12}$ para o delito de vagabundagem iam do açoite público até à morte ${ }^{13}$.

10 O registro deste período foi feito por Rusche e Kirchheimer (1984, p. 12), levando à conclusão de que a "transformación de las tierras agrícolas en tierras de praderas y el surgimiento de sistemas capitalistas de pastoreo produjeron la pauperización de grandes extensiones de territorio, lo cual resultó coincidente con un incremento general de la población en Inglaterra. Las condiciones ventajosas de los artesanos fueron amenazadas por la emigración de campesinos empobrecidos hacia las ciudades. Resultaba ya evidente que los incrementos en la producción no lograban satisfacer el crecimiento demográfico".

11 Segundo Marx (1996, p. 341) "O que faz época na história da acumulação primitiva são todos os revolucionamentos que servem de alavanca à classe capitalista em formação; sobretudo, porém, todos os momentos em que grandes massas humanas são arrancadas súbita e violentamente de seus meios de subsistência e lançadas no mercado de trabalho como proletários livres como os pássaros. A expropriação da base fundiária do produtor rural, do camponês, forma a base de todo o processo. Sua história assume coloridos diferentes nos diferentes países e percorre as várias fases em sequência diversa e em diferentes épocas históricas. Apenas na Inglaterra, que, por isso, tomamos como exemplo, mostra-se em sua forma clássica".

12 Melossi e Paravini (1980, p. 33) acerca deste evento histórico, afirmam que negar-se a trabalhar era considerado uma intenção criminosa, já que o estatuto denominado Old Poor Law, de 1601, facultava ao juiz mandar para o cárcere comum aqueles considerados desocupados.

13 Neste sentido, e seguindo a linha de estudos de Marx (1996, p. 356), o decreto de Henrique vin de 1530 informava que "esmoleiros velhos e incapacitados para o trabalho recebem uma licença para mendigar. Em contraposição, açoitamento e encarceramento 
Apesar da existência de dispositivos legais que enfrentavam o tema, o problema social continuou se agravando ao ponto de, através de uma petição, membros do clero inglês requererem ao Rei que usasse o Castelo de Bridewell como casa de recolha daqueles vagabundos e delinquentes para que, através de uma disciplina para o trabalho, pudessem aprender um ofício que permitisse a própria manutenção. Surge então a "casa de trabalho" (workhouses ${ }^{14}$ ) que, em pouco tempo, como modelo, espalhou-se a diferentes localidades da Inglaterra.

Os que eram levados para habitarem as "casas de trabalho" eram submetidos a um rigoroso tratamento educador para uma reinserção social através do trabalho. $\mathrm{O}$ tratamento executado neste estabelecimento social, agora institucionalizado e dirigido através da mais estrita disciplina, era fiscalizado por comissários (funcionários profissionais) encarregados da manutenção da ordem e da disciplina. Surge então a ideia de um tratamento reeducador associado a uma instituição fechada, uma instituição total.

A estrutura física consistia em grandes prédios. Os homens eram separados das mulheres e as crianças eram separadas em grupos de vinte. Nas paredes dos dormitórios várias mensagens bíblicas eram postas e as orações eram impostas. O mérito ou demérito das pessoas reclusas era aferido pelo seu comportamento e capacidade produtiva ${ }^{15}$. Ao entrar na workhouse, imediatamente era dado à pessoa um uniforme que representava aceitação da disciplina para configuração de um novo ser organizado, ordeiro e atento às novas regras. Na verdade, disciplinava-se a pessoa para ser um verdadeiro combatente no novo sistema de produção. 
Toda esta conjuntura histórica em que se atribui uma função social a uma instituição total em decorrência de um delito, e que termina na ascensão do trabalho como técnica reinsersora por excelência, fez com que Melossi e Paravini (1980) determinassem a não existência do cárcere como instituição social até o período feudal. O carece como estabelecimento social nasce somente a partir da dissolução daquela mesma sociedade feudal, a qual, por sua vez, estruturou uma economia capitalista, sendo que esta, com a pretendida acumulação de capital, fez surgir a instituição como hoje a conhecemos e encontramos. O trabalho penitenciário é o elemento chave que explica a origem da instituição penitenciária e constitui-se num verdadeiro elo entre a pena e esta instituição total.

O trabalho penitenciário nesta época era uma verdadeira obrigação do internado pois, na Inglaterra de 1601, a Lei dos Pobres criou uma espécie de imposto a ser pago pelos mais ricos, destinado à manutenção da workhouse. Em troca, os internados compensavam, trabalhando para aqueles que pagavam o imposto, sob pena de não receberem alimentação ou de terem alguma "regalia" retirada ou negada (Engels, 2008, p. 318)

Logo, o direito passa a ter importante papel na constituição do capital $^{16}$, na manutenção e na promoção da instituição penitenciária. Portanto, faz-se necessário compreender o direito e, sobretudo, sua função ideológica que, com a ascensão do capitalismo, o faz voltar-se contra as classes mais baixas, visando proteger as relações de troca.

Marx via o delito como uma manifestação da desmoralização e decadência da sociedade por conta do processo de acúmulo de capital, que gerava um abismo social estrutural. Os delinquentes, então, teriam estimulado a força produtiva do mundo capitalista que a prisão subtraiu do mundo externo para conter um excesso de mão-de-obra (Taylor, Walton e Young, 1990, p. 226). Logo, o direito é expressão das relações de poder na estrutura social e seus mecanismos regulam e mantêm vivas tais relações.

O comportamento do direito neste cenário foi analisado por Evgeni Pasukanis, que passou a elaborar uma teoria do direito, conferindo particular atenção a uma racionalidade (econômica)

16 O direito é mobilizado, neste cenário, para mediar e perpetuar a submissão econômica de alguns em relação a outros, mesmo antes do trabalhador vender sua força de trabalho (Marx, 1996, p. 210). 
e aos modos em que era posto e proposto o direito. Pasukanis consolidou a ideia de que a Lei era pautada por princípios de individualidade abstrata, por uma relação de equilíbrio entre os atores litigantes e também por igualdades que estabelecem o direito como um contrato (jurídico) das relações sociais ${ }^{17}$.

Para o autor, o direito, ao criar a figura do sujeito de direitos universalizados, direciona-se para um determinado perfil de indivíduo (proletariado). A partir daí, o direito passa a estabelecer as relações comerciais de troca como base contratual das relações jurídicas, sustentando como igual uma estrutura comercial desigual que embrulha com o manto da legalidade. As relações de troca passam a ser normais e justas por serem revestidas de legalidade.

Para Pasukanis, o individualismo abstrato, criado a partir da figura do sujeito universal, iguala a todos diante da lei e esconde as desigualdades inerentes que existem entre as partes e que separam as classes sociais umas das outras. Desse modo, preserva e reforça as relações capitalistas através do discurso e, ao mesmo tempo, esconde mais profundamente os verdadeiros interesses através da universalização e da generalização do discurso que legitima tais relações.

Por sua vez, o direito penal atende igualmente aos desejos do mercado quando a pena estabelece uma espécie de contrato entre a pessoa reclusa e o Estado -como um mecanismo de pagamento de uma dívida contraída- e este contrato é acordado, como no mundo dos negócios, com base na boa-fé e no livre acordo, através de estritas formas e modalidades de procedimentos processuais penais. A função ideológica de controlo é a linha divisória entre os preceitos legais e a realidade do delito, o qual serve como instrumento de dominação protetor do direito de propriedade das classes dominantes (Pasukanis, 1976, pp. 156-157).

Portanto, não é a pena uma simples resposta ao delito, mas um fenômeno social diferente dos fins estabelecidos pelo discurso corrente do direito. A pena em si não existe, o que existe são formas de tratamento das pessoas reclusas, adequadas a um 
sistema de produção que estrutura um domínio classista. Isto explica, historicamente, a composição da população carcerária, que é pobre (Rusche e Kirchheimer, 1984, pp. 17-18). Dito de outro modo, o trabalho penitenciário (travestido de pena sob o discurso da ressocialização) é expressão de preconceitos fundados nas desigualdades sociais.

Rusche e Kirchheimer (1984) acrescentam que a política penal carcerária é flexível sempre que há, no mundo extramuros, grande demanda de mão-de-obra -o que propiciaria o surgimento de políticas estimuladoras do trabalho- e que é inflexível quando o mercado se satura de mão-de-obra. Isso explicaria que as condições no cárcere devam ser, necessariamente, inferiores às condições externas (lei de menor elegibilidade), o que permitirá uma maior valoração do trabalho pelos que habitam o ambiente penitenciário e uma menor valoração do trabalho dos reclusos pelos que desejam a mão-de-obra. O recluso, neste cenário, preferirá o elegível à marginalidade, convertendo-se "voluntariamente" à conformidade.

\section{O mercado e a ressocialização pelo trabalho}

O princípio do mercado cria recursos para sujeitar e controlar as pessoas de acordo com seus interesses. Um destes recursos foi o discurso da ressocialização através do trabalho, que é estruturado para que o corpo social a aceite como verdade universal e a ela se submeta. Logo, a ressocialização é atingida através da disciplina -do corpo- tornando o trabalho a principal tecnologia do poder segregador que valoriza a pessoa pelo que faz e pelo que produz. O ócio é aqui o maior de todos os pecados ${ }^{18}$.

O poder segregador e a disciplina para o trabalho, sempre associados a um sistema de produção, não atingem somente os delinquentes, mas, também, toda classe de pessoas que possuem um baixo poder de consumo (Bauman, 2004, p. 29). Por isso, as pessoas

18 "Se a pena infligida pela lei tem por objetivo a reparação do crime, ela pretende também que o culpado se emende, e esse duplo objetivo será cumprido se o malfeitor for arrancado a essa ociosidade funesta que, tendo-o atirado na prisão, aí viria encontrá-lo de novo e dele se apoderar para conduzi-lo ao último grau de depravação" (Foucault, 2004, p. 202). 
reclusas são ensinadas a trabalhar por trabalhar, para que se garanta que nada possam fazer ao sair da instituição ${ }^{19}$.

O discurso jurídico que pretende ajudar à pessoa foi deixado de lado. O mercado naturalizou as regras que surgiram com a intensificação das relações de troca (livre concorrência, estabelecimento de preços pela demanda e oferta, etc.). De lugar de justiça, o mercado passa a ser lugar de veridição, onde o justo e o injusto já não importam mais diante de uma verdade "natural" que surge em substituição de um racionalismo (jurídico) que sucumbiu diante da nova governamentabilidade que se apresentou (Foucault, 2008, pp. 63-64).

Neste contexto, devemos dar atenção à instituição carcerária que atua nas margens do sistema de produção e de sua lógica, readaptando àqueles que agem contra a razão mercadológica e neutralizando àqueles que não possuem mais oportunidades de readaptação.

Esta realidade é-nos mostrada por Michaël Fœssel (2010) quando afirma:

La société néolibérale organise l'exclusion de ceux qui ne savent pas voir, et demeurent «aveugles» aux opportunités du marché. Ceux-là deviennent coupables par défaut de vigilance. Ils sont des agents irrationnels dans un monde saturé de rationalités techniques et d'informations utiles. (...) Leur fauter é side dans un déficit d'adaptation (Foessel, 2010, p. 46).

Assim, os mecanismos governamentais dirigidos à questão da repressão criminal representam o pilar principal da governamentabilidade neoliberal, já que a racionalidade mercadológica lhes exige dispositivos que tornem os mecanismos de troca mais seguros e menos custosos. Fossel (2010, p. 39) afirma que agora o problema não é definir o que é lícito ou ilícito (como

19 Na mesma linha, ensina Foucault (2004, p. 133) que "em sua concepção primitiva, o trabalho penal não é o aprendizado deste ou aquele ofício, mas o aprendizado da própria virtude do trabalho. Trabalhar sem objetivo, trabalhar por trabalhar, deveria dar aos indivíduos a forma ideal do trabalhador (...). Posteriormente, a partir dos anos 1835-1840, tornou-se claro que não se preocupava por reeducar os delinquentes, torná-los virtuosos, mas sim agrupá-los num meio bem definido, rotulado, que pudesse ser uma arma com fins econômicos ou políticos. O problema então não era ensinar-lhes alguma coisa, mas ao contrário, não lhes ensinar nada para se estiver bem seguro de que nada poderiam fazer saindo da prisão". 
na racionalidade político-jurídica), senão avaliar o limite mínimo do que é tolerável para uma sociedade em relação às suas doenças. Neste contexto, o dispositivo punitivo constitui um processo de desindividualização da insegurança, com cálculos de riscos cuja finalidade é sempre econômica.

Nesta perspectiva, o trabalho pensado desde uma ótica mercadológica cria expectativas e um sistema de gratificação que visa aumentar o rendimento e o produto do trabalho. Para Byung-Chul Han (2015, p. 59) o capitalismo se apropria do trabalho do outro para gerar uma maior produtividade no menor tempo possível, já que capitalismo e trabalho são duas faces da mesma moeda ${ }^{20 .}$

\section{Um novo modelo para a execução penal? Análise conceitual do consensualismo penitenciário}

No ano de 1955, na cidade de Genebra ${ }^{21}$, foram estabelecidas regras em torno da execução de uma pena ordinária dentro da instituição penitenciária com o propósito de criar nos prisioneiros a vontade de levar uma vida de acordo com a lei, e autossustentável quando em liberdade. $\mathrm{O}$ aguçamento de um sentido de responsabilidade ${ }^{22}$ -ou de prática da submissão- seria fruto do trabalho penitenciário que, novamente, surge como protagonista de um novo modelo de tratamento penitenciário ${ }^{23}$ : o tratamento "consensual" 24.

\footnotetext{
20 Neste sentido, Byung-Chul Han (2015, p. 60) ensina-nos que "o próprio homem, com seu general intellect, transforma-se num capital".

21 Primeiro Congresso das Nações Unidas para a Prevenção do Crime e Tratamento dos Infratores. Genebra, 22 de agosto a 3 de setembro de 1955.

22 Portanto, o despertar de um senso de responsabilidade é critério para a inclusão da pessoa reclusa neste modelo de execução penal que tem como propósito "criar uma vontade (na pessoa reclusa) de levar uma vida de acordo com a lei”, já que a ausência de participação da pessoa reclusa, tem como consequência, "entre autres, l'absence de développement du sens des responsabilités qui va gêner la préparation et l'adaptation postérieure à la vie en libertê" (Rodrigues, 2000, p. 160). 23 O "novo" pressupõe a existência de um "velho", algo que evoluiu tornando-se melhor que o velho. Logo, esta nova forma de tratamento penitenciário atende às exigências de uma nova matriz econômica que, a partir da Segunda Guerra Mundial, provocou profundas alterações no mundo do trabalho com o surgimento de uma diretriz baseada numa racionalização da produção (conhecida como lean production), a qual exige uma maior flexibilização das condições de trabalho (Alves, 2005, p. 18). Esta recente diretriz é denominada por Bauman (2001, p. 15) de modernidade líquida.

24 Essa nova forma "consensual" de administração da Justiça Penal é fruto de um processo de revalorização do ser humano como pessoa humana, que passou a ser a base, o
} 
Durante séculos, as relações entre Estado e pessoa desviante eram relações de autoridade, o primeiro decidindo e o segundo obedecendo. Uma vez que tal pessoa tivesse cometido uma infração, a autoridade judicial estabelecia a punição e a autoridade penitenciária velava pelo cumprimento da pena. A vontade da pessoa nunca era levada em consideração, já que o sistema de justiça criminal, marcado pela característica do poder-dever do Estado em perseguir a pessoa desviante, se orientava por uma série de normas de natureza pública.

Dentro deste prisma, a pessoa só possuía vontade manifesta no momento da violação da lei, único momento onde era considerada um sujeito de vontades. Todo o processo social ulterior fazia dele um objeto. A justiça penal estava submetida à noção de imperium.

Com o desenvolvimento das ideias de individualização, de socialização e de ressocialização, com o quadro dos direitos humanos, e igualmente com as conquistas da psicologia, o paradigma do imperium perde força, obrigando à aceitação da ideia de que a pessoa desviante é um sujeito de direito. Estas ideias deram origem a uma justiça penal consensual ou justiça negociada, ainda que estas denominações não possam ser tidas como sinônimas.

Conceitualmente, justiça consensual designaria um "modelo que concede um lugar mais ou menos importante ao consentimento dos interessados, seja sob a forma positiva de uma aceitação ou sob a forma negativa de uma ausência de recusa" (Tulkens e Van de Kerchove, 1996, p. 448). Portanto, este modelo implica a prévia aprovação por parte da pessoa, que não tem capacidade de negociação, em vez de resultar de uma imposição por parte do Estado.

Por seu turno, justiça negociada consiste na possibilidade de atribuir à outra parte um verdadeiro poder de negociação sobre as propostas e, até mesmo, sobre o seu conteúdo, o que daria uma maior autonomia e alternativas de aceitação ou recusa da proposta ${ }^{25}$ (Tulkens e Van de Kerchove, 1996, p. 449).

Em raciocínio diferente, Pradel (2000, p. 146), utilizando o vocábulo consensualismo, o define como princípio pelo qual as partes

objetivo e o limite do Estado. Assim, o Estado deve recuar em seu poder de determinação e passar a agir como garantidor dos direitos do homem (Rodrigues, 2000, p. 149). 25 Neste sentido, Anabela Rodrigues (2000, p. 355) afirma que a justiça imposta cede passo, cada vez mais, a uma justiça negociada, interativa e horizontal, que busca a composição de interesses através da racionalidade dialética. 
que podem negociar no âmbito da justiça criminal afastam, por acordo, a aplicação das regras jurídicas, o que pressupõe trocas, discussões e concessões, para que o ponto de equilíbrio seja encontrado.

Este fenômeno que buscamos entender conceitualmente é uma forma de negociação sobre o processo penal, que se transpôs também para além deste processo de formação e de afirmação da culpa, chegando até à execução da pena ordinária. Seria possível ver, com clareza, consensualismo na execução da pena? De acordo com Pradel (2000, p. 146), não se admite que, em sede de execução da pena, o condenado possa negociar com a Administração Pública as condições de execução de sua penalidade, pois o Direito Penal, compreendendo sua vertente penitenciária, é ordem pública, é interesse geral, enquanto a convenção civil ou comercial é unicamente de interesse privado.

Sob esta ótica, o consensualismo na execução das penas reside na pura e simples aceitação de um benefício oferecido pelas autoridades penitenciárias. Assim, a pena deixa de expressar o imperium puro da justiça penal, e esta passa a considerar o preso como um sujeito de direitos. Desta forma, o Direito Penal busca um caminho original, esforçando-se cada vez mais para executar uma pena de acordo com o consentimento da pessoa, pois a sanção mais útil é a sanção aceita pelo condenado, já que ela estimula sua participação no alcance dos objetivos estabelecidos pelo tratamento penitenciário, lhe devolvendo seu sentido de responsabilidades ${ }^{26}$.

Desta maneira, surge uma imperiosa quebra de paradigma, já que a política da “justa punição” não produziu nenhum resultado satisfatório, e o novo conceito de socialização, pautado no consentimento, buscaria relegitimar socialmente tanto a instituição penitenciária como todo sistema de justiça penal, com a prevalência dos direitos do homem como sujeito de direito ${ }^{27}$. Não haveria aqui uma reeducação imposta, mas sim uma voluntarização à reeducação.

26 Neste sentido Rodrigues (2000, p. 160) afirma que o objetivo deste modelo de justiça penal executora é criar um modelo de prisão não dessocializadora, pautada no consentimento do condenado pois "l'absence de participation a comme conséquence, entre autres, l'absence de développement du sens des responsabilités qui va gêner la préparation et l'adaptation postérieure à la vie en libertê".

27 Neste sentido, Rodrigues (1999, p. 361) afirma que "o renascimento da socialização entrará, no entanto, em perda, se não ocorrer no quadro das garantias jurídicas consubstanciadas no princípio do Estado de direito democrático". 
A base do tratamento voluntário deve prevalecer diante do perigo que representa para os direitos fundamentais da pessoa reclusa a imposição de um tratamento, ou até mesmo de um trabalho forçado. "O tratamento" é sempre um direito do indivíduo e não um dever que possa ser-lhe imposto por constrangimento. O consensualismo permite um afastamento do ambiente prisional para o desenvolvimento de um trabalho de interesse geral quando a administração penitenciária percebe que, no curso da execução da pena, a pessoa reclusa demonstra possuir aptidão para a vida laboral ${ }^{28}$.

O modelo discutido surgiu na década de 90 na França, quando a execução de penas num espaço fechado abriu oportunidades para seu cumprimento fora do estabelecimento social total. As medidas consensuais foram batizadas "grâce conditionnelle" para o trabalho, ou sanção pelo trabalho de interesse geral ${ }^{29}$.

Embora exista a preocupação de ver a pessoa reclusa como um sujeito de direitos capaz de dizer "sim" ou "não" às ofertas de trabalho, ao mesmo tempo não é permitida qualquer forma de discussão em relação às condições deste trabalho. Muito menos há qualquer instrumento desenvolvido capaz de afirmar que um trabalho específico é adequado às vocações laborais da pessoa.

Para que o tratamento consensual tenha êxito faz-se necessário -através da utilização de outras técnicas- evitar que o cárcere produza na pessoa efeitos negativos que inviabilizem o trabalho externo ou até mesmo todo o tratamento ressocializador. Tratase aqui de um alerta feito pela criminologia sobre os efeitos 
negativos ${ }^{30}$ do cárcere na pessoa, os quais enfraquecem disposições ${ }^{31}$ anteriormente construídas e impossibilitam uma vida "ideal" em liberdade.

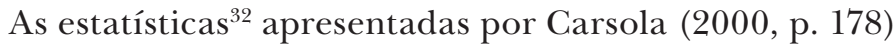
quanto ao produto deste programa são, de certa forma, entusiasmadoras -designadamente no que diz respeito ao índice de não reincidência- numa perspectiva macro. Porém, numa perspectiva micro não nos é revelado se esta forma de trabalho é vocacionada para a vida das pessoas.

\section{O trabalho consensual no Estado do Pará}

Implementado no ano de 2009, o trabalho penitenciário promovido por conta da relação homem-penitenciaria através do programa "Começar de Novo" representou, ao menos no discurso, um exemplo de política pública ressocializadora já que, através do consenso, oportuniza-se à pessoa reclusa uma atividade fora do ambiente do estabelecimento social total.

Para o empregador, o labor das pessoas reclusas representa uma redução de até $50 \%$ no custo de mão-de-obra por pessoa contratada dentro do programa com fundamento na Lei de Execuções Penais. Por comparação com a contratação de "trabalhadores livres", o empregador pode pagar, a título de remuneração, até três quartos do salário mínimo vigente, não havendo custos com encargos sociais

\footnotetext{
30 Segundo Baratta (2004, p. 189), os efeitos negativos que a prisão exerce sobre as pessoas reclusas são resultado de um "processo de socialização" ao qual a pessoa é submetida. Este processo se dá a partir de dois momentos: a) a "desculturação", quando a pessoa é desadaptada às condições necessárias para a vida em liberdade; b) a "aculturação" (ao que se pode chamar também de "prisionalização") quando emergem novas atitudes tendo como parâmetro o modelo de conduta e valores característicos da cultura carcerária.

31 A criminologia utiliza o termo "atitudes" (Baratta, 2004, p. 189). Porém, o termo disposição, que é usado neste artigo, mostra-se o mais adequado, já que permite entender o estado incorporado dos comportamentos individuais criados a partir de contextos sociais objetivos diversos, de modo a permitir uma análise mais profunda das múltiplas realidades que compõem o mundo social da pessoa.

32 Afirma Carsola (2000, pp. 178-180) que o índice de reincidência foi reduzido drasticamente na França, e aponta o consensualismo como instrumento responsável por este êxito na execução de uma pena ordinária. Indica ainda que de um total de 22.534 pessoas reclusas que no ano de 1998 exerceram alguma atividade, somente $43,22 \%$ recebiam alguma remuneração. Porém, do total de acordos firmados entre o sistema de justiça criminal e a pessoa reclusa, $93 \%$ correspondem a pessoas que não reincidiram em qualquer prática delitiva.
} 
ou trabalhistas ${ }^{33}$. O programa é destinado a pessoas enquadradas nas prerrogativas legais que possibilitam o trabalho externo; ou seja, aquelas que se encontram em regime prisional aberto ou semiaberto $^{34}$ de cumprimento de pena. Portanto, não atinge a totalidade do universo prisional e a gestão do programa é realizada pelo Juízo das Execuções Penais.

No Estado do Pará, o programa foi recebido por meio da Portaria 2702/2009, que deu impulso ao início das atividades logo no ano seguinte (2010), e que possui como objeto o desenvolvimento sociocultural para a capacitação e a qualificação, além de contribuir para o acesso da pessoa reclusa ao mercado de trabalho. Em 2010, por meio da Portaria 0134/2010 do Tribunal de Justiça do Estado do Pará, as empresas privadas que prestavam serviços de engenharia ao Tribunal foram obrigadas a abrir vagas para reclusos ${ }^{35}$, tendo sido contratadas 9 pessoas reclusas sob o regime celetista.

No mesmo ano, foram firmados convênios com a Empresa Pública de Correios e Telégrafos ${ }^{36}$ para o oferecimento de 30 vagas e com a status Construções, empresa do ramo da construção civil, para o oferecimento de mais 5 vagas. A maioria das vagas foi disponibilizada em empresas da construção civil, justamente no auge deste setor econômico ${ }^{37}$. Com exceção da empresa pública de Correios, onde somente uma pessoa deixou posteriormente de fazer parte do programa, nas empresas de engenharia, que incorporaram 14 pessoas reclusas, 7 pessoas (metade das incorporadas) deixaram de fazer parte do programa ainda no mesmo ano ${ }^{38}$.

33 O empregador contratará a pessoa reclusa e terá como obrigação somente "o pagamento de salário, alimentação e transporte, salvo nos casos de contratação com registro em Carteira de Trabalho, hipótese em que o preso tem todos os direitos de um trabalhador livre". Disponível em http://www.fiesp.com.br/arquivo-download/?id=1504 34 Segundo o Código Penal brasileiro (arts. 33 a 42), o sistema de cumprimento de penas é progressivo e compõe-se pelo regime fechado (reclusão total em células de contensão); regime semiaberto (reclusão total em células de contensão durante a noite e trabalho durante o dia) e regime aberto (sem reclusão, onde as atividades externas da pessoa reclusa são monitoradas pela administração penitenciária).

35 Quando a pessoa reclusa é inserida no âmbito do programa, o empregador não saberá, ao menos oficialmente, qual foi o crime por ela cometido.

36 No caso da pessoa ser absorvida para o trabalho no setor público de atividades, esta receberá uma bolsa trabalho para efeitos de remuneração.

37 Segundo o Departamento Intersindical de Estatística e Estudos Socioeconômicos, no ano de 2010, a construção civil foi um dos principais carroschefe do crescimento econômico brasileiro, com um crescimento de $14,9 \%$ só no primeiro trimestre de 2010. Disponível em http://www.dieese.org.br/ boletimtrabalhoeconstrucao/2010/2010boletimConstrucaoCivil4.pdf 38 Relatório do programa Começar de Novo no Estado do Pará para o ano de 2010, disponível em http://www.tjpa.jus.br//CMSPortal/VisualizarArquivo?idArquivo=1538 
Nos anos que se seguiram o quadro não foi distinto. Com exceção da empresa pública dos Correios, que absorveu 64 pessoas, 34 das quais não se mantiveram em funções, no ano de 2011 foram inseridas 16 pessoas reclusas, 9 das quais saíram do programa "por motivos diversos", tal como aponta o relatório ${ }^{39}$. Já no ano de 2012, nenhum preso na Região Metropolitana de Belém recebeu autorização para trabalho externo e somente 5 pessoas reclusas receberam essa autorização em todo o Estado do Pará, não especificando o relatório se tais autorizações se referem ou não ao programa em discussão ${ }^{40}$.

Por sua vez, no ano de 2013 registra-se um aumento do número de vagas disponibilizadas por empresas privadas no âmbito do programa. Foram inseridas 51 pessoas em diversas empresas privadas que exploram atividades comerciais diferentes. Porém, a construção civil continua sendo a principal atividade a absorver estas pessoas, 29 das quais ficaram desligadas do programa no mesmo ano. Na esfera pública, os Correios incorporaram 116 pessoas, 86 das quais foram desligadas no mesmo ano. No Tribunal de Justiça, 8 mulheres ${ }^{41}$ foram incorporadas, mas todas se mantiveram ${ }^{42}$. Para os anos posteriores a 2013 não há nenhum dado estatístico disponível.

Os números expostos não demonstram se efetivamente o programa promoveu seu objetivo primordial (a reinserção através do trabalho), mas revelam que um grande número de pessoas foi desligado do programa durante o primeiro ano de atividade, principalmente na esfera privada. Isso faz-nos questionar se as expectativas do programa são realmente percebidas pelas pessoas envolvidas, começando, obviamente, pelas entidades empregadoras. Os dados revelam também que esta forma de trabalho penitenciário não é vocacionada à qualificação pessoal, constituindo-se, sobretudo, como um instrumento de ocupação. Porém, deve discutir-se, também, uma metodologia que seja capaz de identificar as aptidões

39 Relatório do programa Começar de Novo no Estado do Pará para o ano de 2011, disponível em http://www.tjpa.jus.br//CMSPortal/VisualizarArquivo?idArquivo=1556 40 Relatório da Situação Carcerária no Estado do Pará no ano de 2012, disponível em http://www.tjpa.jus.br//CMSPortal/VisualizarArquivo?idArquivo=1541 41 O trabalho destas mulheres limitava-se à digitalização de processos judiciários. 42 Relatório do programa Começar de Novo no Estado do Pará para o ano de 2013, disponível em: http://www.tjpa.jus.br//CMSPortal/VisualizarArquivo?idArquivo=11217 
individuais das pessoas reclusas, o que daria a qualquer relatório quantitativo alguma utilidade científica. Devemos pôr os números à prova do empirismo!

\section{A metodologia da trajetória social individual: A sociologia disposicionalista}

A metodologia eleita em quase todas as investigações que apontam o sucesso ou insucesso de uma política pública voltada para a questão carcerária é, comumente, quantitativa. Quando tratamos do tema "ressocialização", as metodologias qualitativas quase que desaparecem. Embora os dados apresentados por Carsola sejam realmente entusiasmadores, a mera demonstração do sucesso do trabalho "consensual" através de números é cientificamente inútil quando queremos saber os efeitos na vida da pessoa na pós-política pública. Devemos encontrar uma metodologia adequada para explicar se o trabalho exercido por uma pessoa em decorrência da relação penitenciária é ou não vocacionado à sua vida. A metodologia mais adequada será aquela que permita a reconstrução da trajetória individual, com objetivo a detectar o patrimônio de disposições das pessoas. E como estas disposições permitem a execução de um trabalho por conta da relação penitenciária, é importante compreender quais delas são determinantes para o sucesso (ou não) pretendido pelo programa ${ }^{43}$.

Partindo de críticas ao conceito de habitus de Bourdieu, Lahire defende a tese de que o indivíduo possui um conjunto heterogêneo de disposições que deve ser estudado sempre com base empírica ${ }^{44}$,

43 Segundo Bourdieu (1996, pp. 13-33) as disposições -que correspondem a um habitus incorporado pelos indivíduos- não se encontram neles, mas na posição social compartilhada entre as pessoas. Ou seja, todos os indivíduos de uma mesma classe social possuem habitus comuns. Por sua vez, Lahire (2005) avança dos estudos de Bourdieu e argumenta que a vivência social individual é muito mais heterogênea do que homogênea -como pretende seu antecessor-e que o conjunto de práticas incorporadas individualmente pode ou não ter referência com uma estrutura social específica, razão pela qual prefere referir-se ao habitus como um patrimônio individual de disposições. 44 "Os rigores da pesquisa empírica no âmbito das ciências sociais obrigam a não falar nunca de disposições sem apontar as provas empíricas de sua existência” (Lahire, 2004, p. 28). 
atribuindo ao conceito de habitus alguma utilidade científica ${ }^{45}$. Ele propõe uma sociologia em escala individual, onde o comportamento é entendido a partir do conceito de disposição e, para tanto, busca distingui-la e relacioná-la com os conceitos de apetência, agir e crer ${ }^{46}$. Logo é melhor, na perspectiva proposta, que se trabalhem as disposições em vez de um sistema de disposições (que Bourdieu chama de habitus), pois não há somente um princípio gerador, mas vários.

As disposições (que sempre têm uma gênese social) estudadas por Lahire nos levam a diversos contextos de ação nos quais o indivíduo foi inserido durante sua trajetória de vida. É na análise da trajetória de vida que encontramos respostas para os comportamentos individuais. Estas disposições incorporadas formam um patrimônio plural de disposições que devem ser estudadas em cada contexto.

Quanto mais o indivíduo é inserido em diversos contextos da vida (que não são homogêneos e unificados, mas heterogêneos e por vezes contraditórios), mais a trajetória de vida torna-se complexa e seus hábitos podem variar segundo o contexto social em que vive (Lahire, 2005, pp. 26-27). Esta análise contextual ${ }^{47}$ deve

45 Neste sentido, "A partir da constatação da fraca rentabilidade atual da noção de habitus, duas conclusões opostas podem ser tiradas: uma que consiste em pensar que podemos fazer sociologia sem este tipo de conceitos, e que a economia (no sentido duplo do termo) conceitual dos modelos explicativos deve tender a uma depuração do modelo (exit, pois as noções de disposição, de esquema ou de habitus são consideradas supérfluas); a outra conclusão (a qual é formulada visando o desenvolvimento de um programa de sociologia à escala individual) leva-nos a pensar que, daqui em diante, é necessário pôr à prova de investigações empíricas o conceito retórico de habitus para fazê-lo passar a um estatuto de conceito cientificamente útil" (Lahire, 2005, p. 18).

46 Lahire (2005, pp. 18-19) diferencia as disposições para agir das crenças, já que estas "estão já constituídas, e são mais ou menos confirmadas, pela experiência corrente; estão mais ou menos sustentadas pelas múltiplas instituições (escolares, religiosas, políticas, médicas...); e a sua força varia em função do seu grau de constituição (aprendizagem), e posteriormente do seu grau de confirmação (sobre-aprendizagem)". As disposições para agir divergem das crenças, necessariamente, para que se possam explicar os sentimentos de ilusão, frustração e culpabilidade. O autor cita como exemplo: "viver sempre imerso num ambiente ideológico-cultural que valoriza os benefícios do consumo pode levar os atores de uma sociedade a sonhar em aceder ao consumo para se sentir bem, ser felizes ou estar em cima do acontecimento". Mas estes mesmos atores podem estar privados de meios económicos que lhes permitam agir no sentido da sua crença, vivendo essas situações como uma frustração temporária ou permanente. De igual forma, estar “disposto a” não significa fazer com gosto, o que explica muitas disposições a agir sem apetência.

47 No entendimento do autor, "Trata-se não só de comparar as práticas dos mesmos indivíduos em universos sociais (mundos sociais que podem - em alguns casos, mas não sistematicamente - organizar-se sob a forma de campos de lutas) tais como o mundo do trabalho, a família, a escola, a vizinhança, a igreja, o partido político, o mundo dos lazeres, as instituições culturais (...), mas também de diferenciar as situações no interior destes grandes domínios (nem sempre tão claramente separados na realidade social), levando em conta as diferenças intrafamiliares, intraprofissionais..." (Lahire, 2005, p. 28). 
ser posta à prova do estudo empírico, não podendo ser resolvida "antes mesmo de a questão ter sido colocada através da utilização de termos muito constrangedores do tipo "sistema de disposições" (Lahire, 2005, p. 27).

Para responder à dimensão teórica afirmada, Lahire apresenta a técnica dos retratos sociológicos para "avaliar a rentabilidade científica de todo um léxico conceitual disposicional” capaz de "interpretar as variações contextuais dos comportamentos e atitudes de indivíduos singulares" (Lahire, 2004, p. 20). Os retratos representam uma técnica que se utiliza de outra técnica, neste caso a entrevista biográfica, para observar empiricamente as disposições incorporadas pelos atores sociais.

Na análise sociológica em escala individual, com a utilização da entrevista biográfica estamos diante do fato de que o próprio indivíduo investigado narrará sua própria trajetória de vida e que passará inúmeras informações que poderão revelar, mesmo que inconscientemente, aquilo que o investigador quer saber. Logo, "o sociólogo não faz completamente seu trabalho a não ser quando analisa também inúmeros aspectos da vida passada ou presente do entrevistado, que não entram no campo de consciência e de interesse deste" (Lahire, 2004, p. 314). É neste campo de não consciência que a investigação ganhará valiosos dados que poderão responder a seus objetivos.

A narrativa adotará um discurso coerente da trajetória de vida da própria pessoa, cabendo uma análise interpretativa, por meio de sucessivas entrevistas, das disposições mais ou menos frequentes, incorporadas no indivíduo, até que a narrativa atinja uma não consciência que revelará os princípios reitores de seu comportamento. Ensina-nos Lahire (2004, p. 22) que "embora seja suficientemente consciente para nos descrever o que faz, o ator não tem consciência das determinações internas e externas que o levaram a agir como agiu, a pensar como pensou, a sentir como sentiu”.

Uma análise sociológica em escala individual, através da reconstituição sociológica do processo de individualização da pessoa, exige o enfrentamento de dois conjuntos de questões que serão trabalhadas ao longo da investigação: a) os processos de socialização pelos quais as disposições são incorporadas e; b) como este passado incorporado individualmente é reativado. Portanto, a partir do estudo das dimensões especificadas anteriormente, 
é possível identificar disposições mais recorrentes, intensas e regulares para o trabalho, e como elas foram ativadas ou inibidas em decorrência da entrada da pessoa numa instituição total.

Ao lado de outras metodologias qualitativas, os retratos sociológicos apresentam características singulares, já que não se pretende, tão somente através de uma entrevista, uma visão total do entrevistado, mas sim objetivar a subjetividade, capturando as marcas sociais contextualizadas na pessoa; ou seja, relacionar a dimensão macrossociológica com a dimensão individual ${ }^{48}$. $\mathrm{O}$ retrato consiste em estabelecer um tratamento sociológico da individualidade, evitando assim a generalização precipitada do comportamento do indivíduo a partir de um determinado grupo social ${ }^{49}$.

\section{Conclusão}

Exposto o problema, percebe-se que a instituição penitenciária encontrou sua gênese justamente por conta de um problema social relacionado ao trabalho. O trabalho social ensinado numa instituição total, a princípio para conter um excedente de mãode-obra, transformou-se na principal técnica de tratamento penitenciário e assegurou-se ao longo dos anos sempre numa perspectiva positiva e entusiasmadora.

A instituição penitenciária como estabelecimento social surgiu a partir da criação das workhouses e, a partir de então, o modelo espalhou-se pelo mundo, desenvolvendo sutis formas de controlo social através do discurso da recuperação pelo trabalho.

48 Nos estudos de Lahire (2005, p. 14) "estudar o social individualizado, ou seja, o social refractado num corpo individual que tem a particularidade de atravessar instituições, grupos, campos de forças e de lutas ou cenas diferentes, é estudar a realidade social na sua forma incorporada, interiorizada”.

49 As conclusões macrossociológicas resultam num caráter generalizável do indivíduo quando o tomamos por objeto de estudo. Lahire propõe um refinamento dos modelos da macrossociologia através da prova empírica, de tal modo que não se negligencie o caráter complexo, plural e heterogêneo presente na escala individual. Para o autor, "os sociólogos apoiaram-se muitas vezes nessa noção, como na de "generalizabilidade" das disposições e esquemas, para reforçar certa preguiça empírica. Se cada investigação sobre uma ou outra prática permitisse verdadeiramente apreender disposições gerais que se pressupõem transferíveis a outras situações, então evitar-se-ia um longo e fastidioso percurso de pesquisa: precisamente aquele para cuja realização se propõe contribuir uma sociologia à escala individual" (Lahire, 2005, p. 23). 
Transformou-se o trabalho penitenciário numa técnica de adestramento e conformação.

A partir das constantes transformações na estrutura da sociedade, diversas penas foram substituídas, e o procedimento para a execução penal tornou-se mais "humano". Nesta perspectiva, o trabalho deixa de ser uma obrigação da pessoa reclusa e passa a absorver um discurso de direito a ser desenvolvido na forma consensual. Tanto na França como no Brasil (aqui a partir do ano de 2009), relatórios (números) foram divulgados apontando o sucesso desta nova forma de tratamento ressocializador. Nenhuma metodologia qualitativa foi utilizada na elaboração dos relatórios, e muito menos tem existido preocupação com a situação "pós-trabalho penitenciário".

Ao relatar um resultado de política pública, os dados apresentados não são cientificamente úteis sem o estudo de seu principal destinatário, o ator social. E aqui a sociologia disposicional de Bernard Lahire encontra abrigo e é a mais adequada para capturar as variações nas disposições ao longo da trajetória de vida da pessoa reclusa. Esta é uma maneira de tratar a individualidade a partir da compreensão de todo o percurso institucional da pessoa.

Com o uso da técnica dos retratos sociológicos, a investigação levada a cabo na Universidade de Coimbra colocará à prova os resultados quantitativos apresentados pelo Conselho Nacional de Justiça e buscará determinar, a partir da sociologia em escala individual, os efeitos da (contra) socialização penitenciária. A partir do uso da técnica em questão, determinar-se-á se o trabalho desenvolvido por conta da relação penitenciária é ou não vocacionado à vida da pessoa.

\section{Referências}

Alves, G. (2005). O novo (e precário) mundo do trabalho: reestruturação produtiva e crise do sindicalismo. São Paulo: Boitempo Editorial.

Baratta, A. (1986). Viejas y nuevas estrategias en la legitimación del derecho penal. Poder y Control, Revista hispanoamericana de disciplinas sobre el control social. Barcelona: Promociones y Publicaciones Universitarias.

Baratta, A. (2004). Criminología crítica y crítica del derecho penal: Introducción a la sociología jurídico penal. Buenos Aires: Siglo XXI. 
Bauman, Z. (2001). Modernidade líquida. Rio de Janeiro: Jorge Zahar.

Bauman, Z. (2004). Amor Líquido: sobre a fragilidade dos laços humanos. Rio de Janeiro: Zahar.

Beristain, A. (1982). La pena retribución y las actuales concepciones criminológicas. Buenos Aires: Depalma.

Bourdieu, P. (1996). Espaço social e espaço simbólico. Razões práticas: sobre a teoria da ação. Campinas: Papirus.

Bourdieu, P. (2009). A economia das trocas simbólicas. Condição de classe e posição de classe. São Paulo: Perspectiva.

Byung-Chul, H. (2015). Piscopolítica. Lisboa: Relógio D’água.

Carsola, F. (2000). Du consensualisme en prison en droit pénitentiaire français. Journées Internationales de la Foundation Pénale et Pénitentiaire, Lisboa. Nouvelles Orientations du Régime Pénitentiaire.

Crowther, A. (1982). The Workhouse System. 1834-1929. Georgia: The University of Georgia Press.

Engels, F. (2008). A situação da classe trabalhadora na Inglaterra. São Paulo: Boitempo.

Fœssel, M. (2010). Etat de vigilance: Critique de la banalité sécuritaire. Paris: Le Bord de l'eau.

Foucault, M. (2004). Microfísica do Poder. Rio de Janeiro: Edições Graal.

Foucault, M. (2008). Nascimento da Biopolítica. São Paulo: Martins Fontes.

Lahire, B. (2004). Retratos sociológicos: disposições e variações intraindividuais. Porto Alegre: Artmed.

Lahire, B. (2005). Patrimônios individuais de disposições: para uma sociologia à escala individual. Sociologia: problemas e práticas, n. 49.

Lima, F., Oliveira, M., \& Wilrich, J. (2012). Relato de experiência - a arte como instrumento de reinserção social. Journal of Nursing and Health, 2, 265-275.

Marchiori, H. (1985). Institución Penitenciaria. Córdoba: Marcos Lerner.

Marques, T. (2013). Crime and The Fascist State, 1850-1940. Londres:

Pickering \& Chatto.

Marx, K. (1996). O Capital. Crítica da economia política. São Paulo: Nova Cultural.

Melossi, D., \& Paravini, M. (1980). Cárcel y fábrica. Los orígenes del sistema penitenciario, siglos XVI - XIX. Bogotá: Siglo XXI.

Onofre, E., \& Julião, E. (2013). A educação na prisão como política pública: entre desafios e tarefas. Educação E Realidade, 38(1), 51-69.

Pasukanis, E. (1976). Teoría General del Derecho y Marxismo. México DF: Editorial Grijalbo S.A.

Pradel, J. (2000). La notion de consensualisme en droit de l'exécution de la peine. Journées Internationales de la Foundation Pénale et Pénitentiaire. Lisboa: Nouvelles Orientations du Régime Pénitentiaire.

Rodrigues, A. (1999). Consensualismo e prisão. Boletim Documentação e Direito Comparado, Lisboa, n. 79/80.

Rodrigues, A. (2000). Consensualisme et prison. Journées Internationales de la Foundation Pénale et Pénitentiaire. Lisboa : Nouvelles 
Orientations du Régime Pénitentiaire.

Roxin, C. (2004). Problemas Fundamentais de direito penal. Lisboa: Veja.

Rusche \& Kirchheimer (1984). Pena y estructura social. Bogotá: Temis.

Santos, B. (1999). Pela mão de Alice. O social e o político na pós-modernidade. Porto: Afrontamento.

Shecaira, S. (2004). Criminologia. São Paulo: Editora Revista dos Tribunais.

Taylor, I., Walton, P., \& Young, J. (1990). La nueva criminología - Contribución a una teoría social de la conducta desviada. Buenos Aires: Amorrortu.

Tulkens, F., \& Van de Kerchove, M. (1996). La justice pénale: Justice imposée, justice participative, justice consensuelle u justice négociée? Revue de Droit Pénal et de Criminologie. Bruxelas. 